\section{Use of Digital Images for Evaluation of Factors Responsible for Visual Preference of Apples by Consumers}

\author{
Margaret Cliff ${ }^{1}$ \\ Agriculture and Agri-Food Canada, Pacific Agri-Food Research Centre, \\ Summerland, British Columbia VOH 1ZO
}

Katherine Sanford

Agriculture and Agri-Food Canada, Atlantic Food and Horticulture Research Centre, Floor 2nd, Room C-244,32 Main Street, Kentville, Nova Scotia B4N 1 J5

\author{
Wendy Wismer ${ }^{2}$ \\ Department of Agricultural, Food and Nutritional Science, University of \\ Alberta, Edmonton, Alberta T6G 2P5
}

\section{Cheryl Hampson \\ Agriculture and Agri-Food Canada, Pacific Agri-Food Research Centre, Summerland, British Columbia VOH $1 \mathrm{ZO}$}

Additional index words. consumer preference, apple preference, visual characteristics, Malus $\times$ domestica

\begin{abstract}
This research used digital images to explore some of the factors responsible for consumer preference of visual characteristics of apples (Malus $\times$ domestica Borkh.). The images systematically varied in color and shape (Expt. A: 9 images) and type, shape, and background color (Expt. B: 10 images), while keeping apple size constant. Visual assessments of the apple images were collected from 144 consumers (Expt. A) and 165 consumers (Expt. B) in British Columbia (BC), Nova Scotia (NS), and New Zealand (NZ) using balanced incomplete block designs. Canadian consumers (BC and NS) preferred red apples over green or yellow. NZ consumers liked equally red and green apples, and preferred both to yellow apples. At all locations, consumers in Expt. A significantly preferred round and conical shaped apples to oblong apples. When the combined effects of type, shape, and background color were evaluated, NZ consumers rated the striped, round apples the highest, and least preferred both round and oblong, blush-type apples with yellow backgrounds. NS consumers tended to prefer blush apples regardless of type and background color, and $\mathrm{BC}$ consumers were more accepting of a range of apple types, shapes, and background colors.
\end{abstract}

Consumer preference for new apple cultivars is extremely complex and not well understood. In general, consumer preference is dependent on familiarity, socioeconomic status, age, gender, culture, and social norms (Lyman, 1989; Andani and MacFie, 2000). For fruit and vegetables, appearance plays a major role in consumer assessment of quality (von Alvensleben \& Meier, 1990) and purchase intent (Crassweller and Hollender, 1989).

Regional apple preferences within Canada

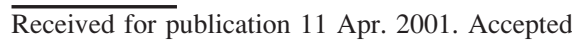
for publication 2 Oct. 2001. Contribution No. 2118. We would like to acknowledge the assistance of Michael Weis, John Hall, Marj King, and Kimberly Dever of the Pacific Agri-Food Research Centre (Summerland, B.C.), Ken McRae, Vivian Agar, Christine Burbidge-Boyd, and Connie Foote of the Atlantic Food and Horticulture Research Centre (Kentville, N.S.) and Dogan Yuksel of the Food Innovation Center (Portland, Ore.).

${ }^{1}$ To whom reprint requests shuld be addressed. E-mail address: cliffm@agr.gc.ca

${ }^{2}$ Work conducted at Hort Research Auckland, New Zealand. have been demonstrated (Cliff et al., 1999) to differ with British Columbian (BC) consumers preferring the appearance of 'Gala' and 'Creston' apples and Nova Scotian (NS) consumers preferring the appearance of 'Fiesta' and 'Cortland' apples. In the international marketplace, 'Granny Smith' and 'Newtown' have been shown to be most preferred in the United States, but not in Asia (Stebbins, 1994).

Dalliant-Spinnler et al. (1996) used internal and external preference mapping to relate consumer preference of apple varieties with a profile from a trained sensory panel, thereby identifying the most relevant sensory attributes. Two external attributes (white specks, looks hard) were found to be significantly correlated with consumer preference for southern hemisphere apples.

Hampson and Quamme (2000) also studied consumer preference of visual attributes in apples. They found that panellists liked the most common shapes, but that lenticels and russet became unacceptable when they exceeded $1.0 \mathrm{~mm}$ or $55 \%$ of the fruit diameter, respectively.
Apple breeding is a challenging task because of the need to screen a large number of seedlings combined with the difficulty of "short-listing" the most relevant attributes for the consumer and their relative importance. This challenge is made even more difficult because apple characteristics do not vary systematically. For example, variables such as size, shape, and color all vary concomitantly from cultivar to cultivar and cannot be easily studied in isolation from one another.

With digital imagery, photographic images can be electronically modified to systematically study visual traits in apples. The objective of this work was to examine some of the factors responsible for consumer preferences of visual characteristics of apples using digitally modified images. This research was implemented in a series of two experiments which evaluated apple color and shape (Expt. A), and apple type, shape, and backgroundcolor (Expt. B). Two apple images, A8 and A9 (Table 1) were included in Expt. B as B1 and $\mathrm{B} 2$, respectively, so that the mean preference scores for the two experiments could be compared.

\section{Materials and Methods}

Apple image creation. Two apples from each of the following cultivars ('Delicious', 'Gala', and 'McIntosh') were photographed using a 35-mm camera containing Kodak professional slide film. One apple was oriented on its side to obtain a 'calyx' view, while the other apple was left standing to obtain a lateral/top view. The film was developed and scanned using Kodak Professional RFS 3570 Film Scanner (Eastman Kodak Co., Rochester N.Y.) with an image size of $3072 \times 2048$ pixels. Images were then edited using Adobe Photoshop version 5.0 (Adobe Systems, San Jose Calif.) on a Power Macintosh 7300/200 computer.

Photographic images were modified to create conical, round and oblong shaped apple images; shapes which were consistent with 'Gala', 'McIntosh', and 'Delicious' apples, respectively. The size of all images was standardized to a diameter of $7.5 \mathrm{~cm}$. This size has been shown to be "ideal" by BC consumers (Hampson \& Quamme, 2000) and preferred by German, Dutch, and British consumers (Goedegebure et al., 1990).

For each shape, three color images (red, yellow, and green) were digitally created. These images served as templates for the creation of images for striped and blushed apples. Photographic images of 'Gala' (stripe) and 'McIntosh' (blush) were transformed to the selected shapes (as described above) using MORPH software version 2.5 (Gryphon Software Corp. 1992-94, San Diego, Calif.). Care was taken to match the orientation of the apples, so that the 'stripes' or 'blush' on the original images were aligned with the contours of the digital images. This ensured that the 'shadows' and 'highlights' were in the appropriate locations and the resultant transformations were as realistic as possible. However, for the stripe and blush apples, it was only practical to create 
Table 1. Color, type, shape, and color characteristics of digital images used for Expts. A and B.

\begin{tabular}{|c|c|c|c|c|c|c|c|c|c|c|c|c|c|c|}
\hline \multirow[b]{2}{*}{ Apple No. } & \multicolumn{3}{|c|}{ Color } & \multicolumn{3}{|c|}{ Shape $^{2}$} & \multicolumn{2}{|c|}{ Background color } & \multicolumn{3}{|c|}{ Over color } & & & \\
\hline & Green & Yellow & Red & Conical & Round & Oblong & Green & Yellow & $\mathrm{L}$ & $\mathrm{a}$ & $\mathrm{b}$ & & & \\
\hline & & & & \multicolumn{8}{|c|}{ Expt.A } & & & \\
\hline A1 & $\mathrm{X}$ & & & & & & NA & & 68.10 & -17.29 & 44.95 & & & \\
\hline A3 & $X$ & & & & & $\mathrm{X}$ & $\mathrm{NA}$ & & 64.97 & -19.78 & 43.13 & & & \\
\hline A4 & & $X$ & & $X$ & & & $\mathrm{NA}$ & & 83.14 & -5.19 & 45.75 & & & \\
\hline A5 & & $X$ & & & $X$ & & $\mathrm{NA}$ & & 81.54 & -5.40 & 42.93 & & & \\
\hline A6 & & $X$ & & & & $X$ & $\mathrm{NA}$ & & 80.95 & -4.14 & 37.56 & & & \\
\hline \multirow[t]{2}{*}{ A9y } & & & $\mathrm{X}$ & & & $\mathrm{X}$ & $\mathrm{NA}$ & & 39.19 & 30.14 & 14.49 & & & \\
\hline & \multicolumn{3}{|c|}{ Type } & \multicolumn{3}{|c|}{ Shape $^{z}$} & \multicolumn{2}{|c|}{ Background color } & \multicolumn{3}{|c|}{ Over color } & \multicolumn{3}{|c|}{ Ground color } \\
\hline Apple No. & Solid & Stripe & Blush & Conical & Round & Oblong & Green & Yellow & $\mathrm{L}$ & $\mathrm{a}$ & $\mathrm{b}$ & $\mathrm{L}$ & $\mathrm{a}$ & $\mathrm{b}$ \\
\hline \multicolumn{15}{|c|}{ Expt. $B$} \\
\hline $\mathrm{B} 1^{\mathrm{y}}$ & $\mathrm{X}$ & & & & $X$ & & NA & & 39.40 & 25.62 & 12.23 & & & \\
\hline B7 & & & $\mathrm{X}$ & & $\mathrm{X}$ & & $\mathrm{X}$ & & 42.39 & 32.68 & 14.79 & 85.30 & -4.54 & 22.22 \\
\hline B8 & & & $X$ & & $X$ & & & $X$ & 43.05 & 32.08 & 12.46 & 86.26 & 2.23 & 24.39 \\
\hline B9 & & & $\mathrm{X}$ & & & $\mathrm{X}$ & $\mathrm{X}$ & & 43.51 & 30.32 & 12.02 & 86.53 & -3.60 & 21.35 \\
\hline $\mathrm{B} 10$ & & & $\mathrm{X}$ & & & $\mathrm{X}$ & & $\mathrm{X}$ & 40.71 & 34.73 & 14.09 & 80.57 & 2.62 & 28.01 \\
\hline
\end{tabular}

${ }^{2}$ Conical, round, oblong refer the shape most usually associated with 'Gala', 'McIntosh', and 'Delicious' apples, respectively.

${ }^{y}$ Apples A8 and A9 are the same as B1 and B2.

Conical, round, oblong refer the shape most usually associated with 'Gala', 'McIntosh', and 'Delicious' apples, respectively.

$\mathrm{NA}=$ Not applicable.

two distinct shapes (round, oblong). All images were created with an identical stem.

All images were printed on a Kodak 8600 Dye-sublimation printer to a standardized diameter of $7.5 \mathrm{~cm}$. Images were cropped to a dimension of $7.6 \mathrm{~cm} \times 15.2 \mathrm{~cm}$, labeled with three-digit random numbers and laminated to protect them during multiple consumer evaluations. The final printed color of the images (L, a, b) for Expts. A and B was measured using a Minolta color meter (Minolta Camera Co. Osaka, Japan) (Table 1). The electronic measurements were taken from locations on the images which were neither in "shadow" or "highlights".

Experimental design. Research was implemented using two experiments (Expt. A, Expt. B) (Table 1).

Expt. A consisted of a $3 \times 3$ factorial design, with nine digital images that varied in color (green, yellow, and red) and shape (conical, round, and oblong) as shown in Table 1. It was implemented using a balanced incomplete block (BIB) design Plan $11.13(\mathrm{t}=9$, $\mathrm{k}=6, \mathrm{r}=8, \mathrm{~b}=12)($ Cochran and Cox, 1957), where each consumer evaluated six of the nine images. This plan was evaluated 12 times for a total of 144 evaluations. Three-digit random numbers were assigned to the images. Treatments, blocks and sample order within blocks were all randomized. Representative images for Expt. A are shown in Fig. 1.

Expt. B consisted of a $2 \times 2 \times 2$ factorial design, with eight images of red apples that varied in apple type (stripe/blush), shape (round, oblong), and background-color (green, yellow) as shown in Table 1. Two additional images, taken from Expt. A, of solid red apples, one of each shape, with no background color were included. The experiment

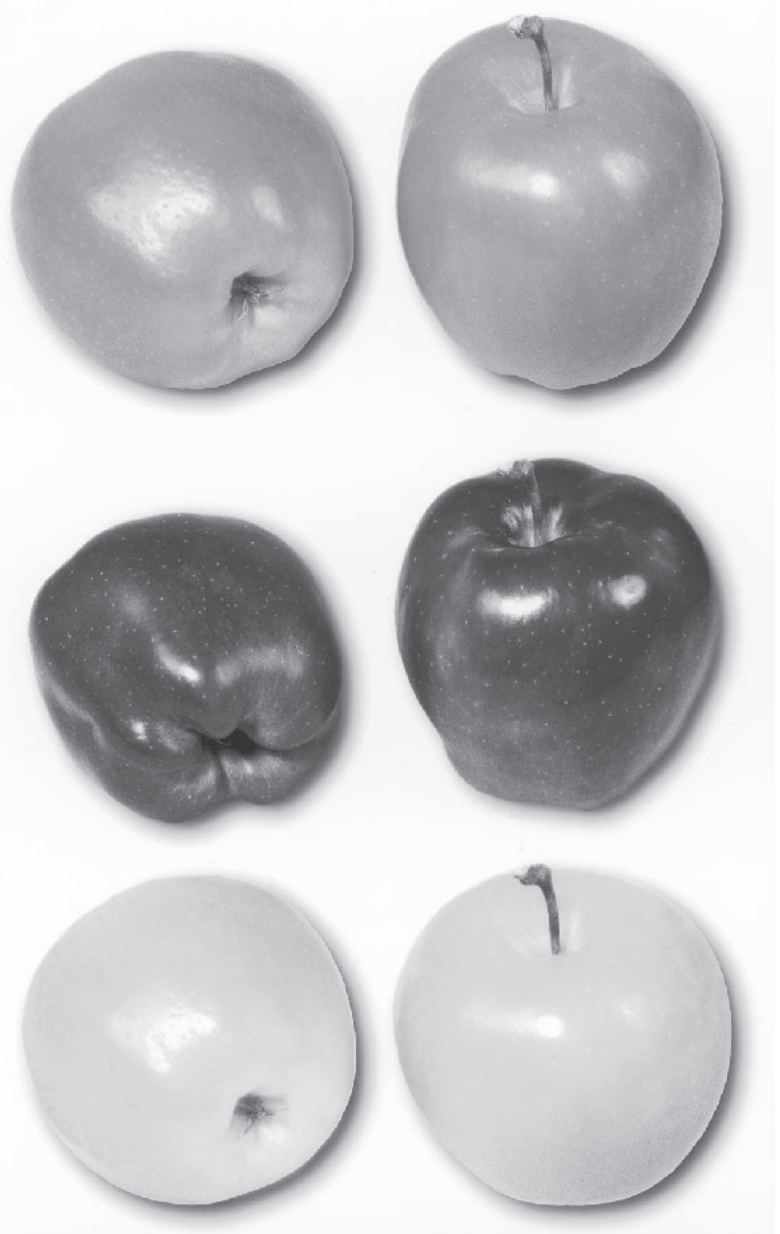

Fig. 1. Examples of digital images used for Expt. A. Images correspond to apples A1 (green, conical), A9 (red, oblong), and A5 (yellow, round), respectively, as listed in Table 1. 
was implemented using a BIB design (plan $11.18(\mathrm{t}=10, \mathrm{k}=6, \mathrm{r}=9, \mathrm{~b}=15)($ Cochran and Cox, 1957), where each consumer evaluated six of the 10 images. This plan was evaluated 11 times for a total of 165 evaluations. Randomization was as described for Expt. A. Representative images for Expt. B are shown in Fig. 2.

Locations. The sensory testing took place in three locations. Consumers at all locations $(5<$ age $<85)$ and were recruited from individuals who liked apples and who were interested in evaluating "new" cultivars. In BC, two different venues were used for Expt. A; one for consumers and the other for professionals employed in the apple industry. The BC consumervenue was at the Apple Orchard Museum (Kelowna, B.C.), where consumers (55\% female, $45 \%$ male) were recruited from attendees to "Apple Day". At this venue, 62\% of the participants were between the ages of 20 and 50. A second venue with industry professionals $(20<$ age $<70)$ was held during the "Hort Forum" at the Trade and Convention Centre (Penticton, B.C.). The NS consumer venue took place at Acadia Univ. (Wolfville, N.S.) where consumers (65\% female, $35 \%$ male) were recruited from campus and the community. At this venue, $67 \%$ of the participants were between the ages of 20 and 50 . The New Zealand (NZ) consumer venue took place at a shopping mall (Auckland, N.Z.), where consumers $(70 \%$ female, $30 \%$ male) were recruited by interception. At this venue, $60 \%$ of the participants were between the ages of 20 and 50.

Booth set-up/scorecard. At the BC and NZ consumer venues, assessments took place in individual "tasting" booths or stations. For the professional evaluation, assessments were conducted at individual "tasting" stations, delimited by white placemats. Photos were arranged in two horizontal rows of three and evaluated against a white background.

Consumers were asked to look closely at each of the six apple images and evaluate them as if they were purchasing them in the grocery store. They were asked to indicate how much they liked the appearance, on a $12.5 \mathrm{~cm}$ (5-point) hedonic line scale, labeled with "dislike-very-much," "dislike-moderately," "neither-like-nor-dislike," "likemoderately," and "like-very-much" at 0,3 , $6.3,9.5$, and $12.5 \mathrm{~cm}$, respectively. Consumers were allowed to pick up the pictures for closer examination, but not allowed to rearrange them. After each subject completed the test, the images were rearranged according to

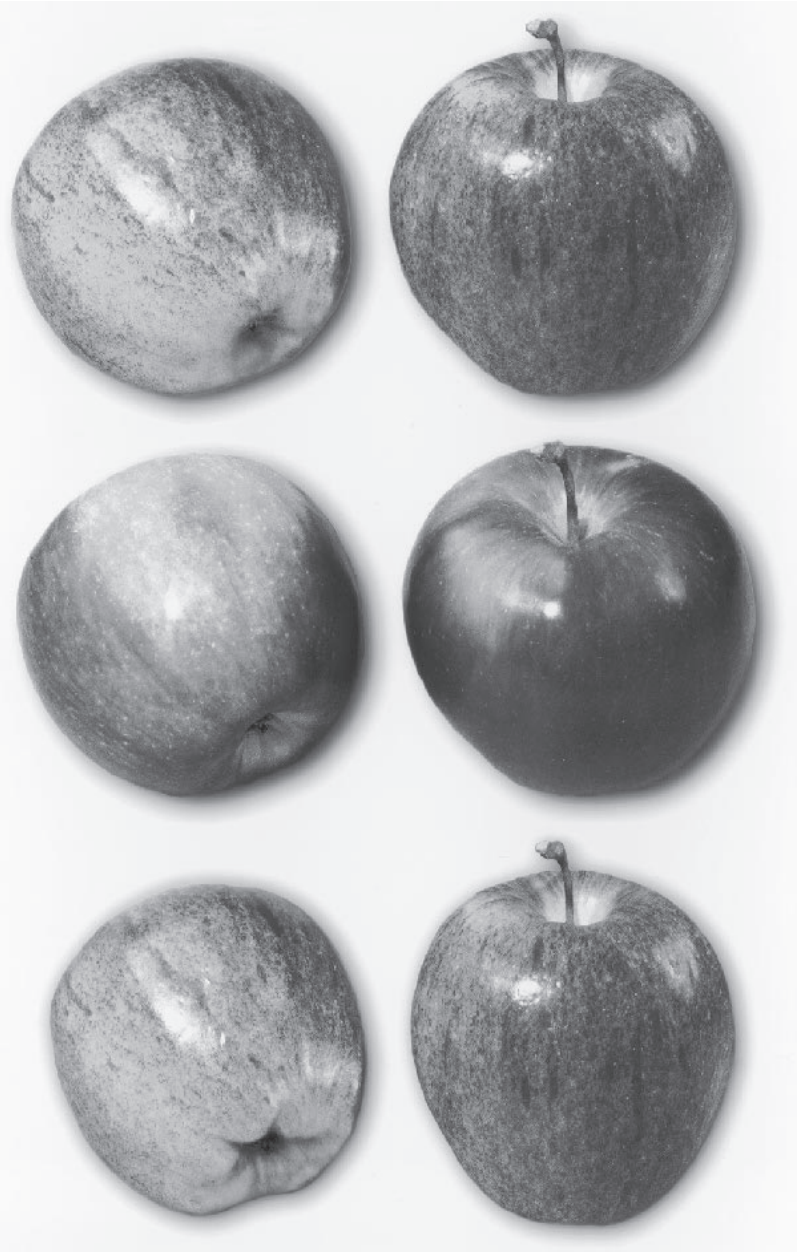

Fig. 2. Examples of digital images used for Expt. B. Images correspond to apples B3 (stripe, round, green background), B10 (blush, round, yellow background), and B6 (stripe, oblong, yellow background), respectively, as listed in Table 1. the order specified by the balanced incomplete block (BIB) experimental design.

Upon completion, consumers were thanked for their contribution and were allowed to select an apple of their choice from red, green, and yellow apples. Their selections were recorded. Consumer data were quantified by measuring the their response in centimetres on the line scales $(\max =12.5)$, with an accuracy of $0.1 \mathrm{~cm}$.

Statistical analysis. Preliminary data analysis demonstrated that data (residuals) from Expts. A and B were sufficiently normally distributed to warrant the use of parametric statistics. Data were then analyzed using a general linear model (GLM). For Expt. A, the following main effects [location, block, color, shape] and interactions [location*block, location*color, location* shape, color*shape, location*color*shape] were evaluated. For Expt. B, the following main effects [location, block, type, shape, background-color] and interactions [location* block, location*type, location*shape, location*background, type*shape, type* background, shape*background, location*type* background*shape, location*block*type* shape*background] were evaluated. For calculation of the F statistic, location and block were considered random effects, with the variation from location*block used as the denominator in the $\mathrm{F}$ test. The remaining effects were considered fixed and the variation from location*color*shape*block and location*type*shape*background*block were used as the denominator in the F-test for Expts. $\mathrm{A}$ and $\mathrm{B}$, respectively. All statistical analysis were conducted using SAS software (SAS Institute, Cary N.C.).

\section{Results and Discussion}

Expt. A. Apple preferences varied by location $(\mathrm{F}=9.79 P=<0.0001)$, color $(\mathrm{F}=141.85$, $P<0.0001)$, shape $(\mathrm{F}=146.337, P<0.0001)$, location*color $(\mathrm{F}=26.84 P<0.0001)$ and location*shape $(\mathrm{F}=9.65 P<0.0001)$. The location was a significant source of variation. On average, consumers in NS had significantly higher mean preference scores $(\bar{x}=8.6$ $\mathrm{n}=864)$, than $\mathrm{BC}(\overline{\mathrm{x}}=8.1 \mathrm{n}=870)$ and NZ $(\bar{x}=7.9 \mathrm{n}=862)$ consumers.

Apple color was a significant source of variation with the results varying by location. On average, red apples had the highest mean score $(\bar{x}=9.4 n=865)$, and yellow apples the lowest ratings ( $\bar{x}=6.8 n=865)$ (Table 2$)$. BC and NS consumers preferred red apples to green and yellow, while NZ consumers liked equally the red and green apples. The second choice for NS consumers was green apples. In contrast, the BC consumers did not significantly prefer the green over the yellow apples. Like the Canadian consumers, the BC "professionals" gave the highest scores to red cultivars. However, their second and third choices were yellow and green, respectively. This difference between consumers and "professionals" may be due to their informed knowledge about new cultivars, particularly yellow cultivars such as Silken, which is known for its 
Table 2. Mean preference scores for digital images for color and shape (Expt. A) for British Columbia (BC), Nova Scotia (NS), and New Zealand (NZ) consumers.

\begin{tabular}{|c|c|c|c|c|c|c|c|c|c|}
\hline Location & Apple color & Mean $^{2}$ & $\mathrm{SE}^{y}$ & $\mathrm{~N}$ & Location & Apple shape & $\operatorname{Mean}^{2}$ & $\mathrm{SE}^{y}$ & $\mathrm{~N}$ \\
\hline$\overline{\mathrm{BC}}$ & green & 7.4 & 0.21 & 290 & $\mathrm{BC}$ & conical & 8.5 & 0.19 & 288 \\
\hline $\mathrm{BC}$ & yellow & 7.2 & 0.21 & 290 & $\mathrm{BC}$ & round & 8.4 & 0.20 & 291 \\
\hline $\mathrm{BC}$ & red & 9.6 & 0.18 & 290 & $\mathrm{BC}$ & oblong & 7.3 & 0.22 & 291 \\
\hline NS & green & 8.9 & 0.19 & 288 & NS & conical & 9.0 & 0.17 & 288 \\
\hline NS & yellow & 7.1 & 0.21 & 288 & NS & round & 9.0 & 0.19 & 288 \\
\hline NS & red & 9.7 & 0.15 & 288 & NS & oblong & 7.7 & 0.21 & 288 \\
\hline NZ & green & 8.6 & 0.21 & 287 & NZ & conical & 8.2 & 0.22 & 289 \\
\hline NZ & yellow & 6.2 & 0.24 & 287 & NZ & round & 8.6 & 0.22 & 286 \\
\hline NZ & red & 8.9 & 0.21 & 287 & NZ & oblong & 7.00 & 0.24 & 287 \\
\hline $\mathrm{BC}$ (professionals) & green & 6.5 & 0.20 & 288 & BC (professionals) & conical & 8.4 & 0.20 & 288 \\
\hline $\mathrm{BC}$ (professionals) & yellow & 8.0 & 0.20 & 288 & BC (professionals) & round & 9.0 & 0.20 & 288 \\
\hline $\mathrm{BC}$ (professionals) & red & 8.4 & 0.20 & 288 & BC (professionals) & oblong & 5.5 & 0.20 & 288 \\
\hline
\end{tabular}

${ }^{2}$ Sensory scores were collected on a 12.5-cm hedonic line scale, labeled with "dislike-very-much," "dislike-moderately," "neither-like-nordislike," "like-moderately," and "like-very-much" at $0,3,6.3,9.5$, and $12.5 \mathrm{~cm}$, respectively.

'Least significant difference between means is about three standard errors (SE) (Hall, 1997).

good flavor and texture (Cliff et al., 1999).

Similarly, fruit shape had a significant effect on consumer preference. On average, round $(\bar{x}=8.7 n=865)$ and conical $(\bar{x}=8.6$ $\mathrm{n}=865$ ) were the most preferred, and both scored significantly higher than the oblong apples $(\bar{x}=7.3 \mathrm{n}=866)$. This trend was consistent for all three locations (Table 2). As indicated by the shape by location interaction, scale usage in the three locations did vary, with NZ consumers showing the largest difference in mean score between the conical $(\bar{x}=8.2 n=289)$, round $(\bar{x}=8.6 n=286)$ and oblong $(\bar{x}=7.0 n=287)$ apples. Hampson and Quamme (2000) found similar results showing oblong apples were disliked by consumers. It is speculated that the low mean score for the oblong shape may have been due to similarity to 'Delicious', an older cultivar known to acquire a mealy texture and poor flavor with storage. It is well documented that consumers desire crisp not mealy apples (Daillant-Spinnler et al., 1996; Hampson et al., 2000; Warner, 1991). This expectation or "shape bias" was even more evident among industry professionals, where oblong apples received the lowest mean score $(\mathrm{x}=5.5 \mathrm{n}=$ 288) of all the evaluations. In 1990, von Alvensleben \& Meier characterized this type of consumer behavior, where a negative image can distort perceptions as the result of a "halo" effect.

Expt. B. Apple preferences were significantly affected by shape $(\mathrm{F}=46.21, P=$ $0.0165)$, type $*$ background-color $(\mathrm{F}=19.87$ $P=<0.0001)$, location*type $(\mathrm{F}=27.73 P<$ $0.0001)$, location*background-color $(\mathrm{F}=9.21$ $P=0.0001)$, type $*$ shape $(\mathrm{F}=4.62 P=0.0328)$ and location*type*background-color*shape $(\mathrm{F}=12.31 P=0.0136)$.

The significant location*type*shape* background-color interaction reveals that preferences for apple appearance was location dependent (Table 3). In general, the BC consumers were accepting of both striped and blush-type apples. Regardless of shape, $\mathrm{BC}$ consumers preferred green backgrounds for the blush-type apples, and yellow backgrounds for striped apples. The least preferred combination was the striped, oblongshaped apple with a green background $(\bar{x}=$
7.3). The $\mathrm{BC}$ consumer is routinely exposed to a wide selection of fresh apples of blushtype ('Spartan', 'McIntosh', 'Empire') and striped ('Gala', 'Creston') apples. Possibly, this has made them accepting of both types of apples. The NS consumer showed a definite preference for the blush-type apples. All four blush-type treatments received the highest mean ratings for liking, with the highest rating going to the blush, round apple with a green background ( $x=9.3$ ). One of the most popular apple varieties in NS is the 'McIntosh', a round, blush-type apple with a green background. The results suggest that NS consumers prefer green backgrounds with blushtype apples, and round rather than oblong shaped striped apples.

In contrast, NZ consumers rated the striped, round apples the highest ( $x=9.5$ ), and least preferred both round and oblong, blush-type apples with yellow backgrounds, with means scores of. 8.1 and 7.6, respectively (Table3). In general, the scores showed a trend for NZ consumers to like apples with stripes, and in most cases a green background. Striped round apples scored higher than the blush-type with a comparable background color. The only blush-type to score as high as its striped counterpart was the blush, oblong apple with a green background. For each pair of apples of the same type and shape, the scores for the green background apple was always slightly higher. NZ has successfully marketed quality striped-type apples such as 'Gala'. Possibly, this has influenced their liking for selected appearance characteristics.

Consistent with Expt. A, BC, NS, and NZ consumers preferred round solid-red apples compared to oblong solid-red apples (Table 3). Of all apples in Expt. B, the round solidred colored apples had the highest mean scores by the BC $(\bar{x}=9.9)$ and NS $(\bar{x}=10.0)$ consumers and the second highest score by the NZ $(\bar{x}=9.2)$ consumers, who preferred round striped apple $(\bar{x}=9.5)$. This is consistent with Leonard \& Wadsworth (1989) who report that consumers have a strong preference for apples with a high percentage of red color and the Canadian Horticultural Council (1979) who report a preference for red apples in the local (Canadian) marketplace. It appears that NZ consumers recognized and preferred the characteristics associated with the locally developed Gala apple (round, striped).

While there were no age-related differences in apple preference among consumers, female consumers had slightly higher mean preference scores $(\bar{x}=8.4 \mathrm{n}=1558)$ than male consumers ( $\bar{x}=7.9 \mathrm{n}=1014)$ in Expt. A. In Expt. B, scores for the females ( $\bar{x}=8.6$ $\mathrm{n}=1814)$ and males $(\bar{x}=8.8 \mathrm{n}=1132) \mathrm{did}$ not differ.

Upon completion of the visual assessment, $54 \%, 42 \%$ and $47 \%$ of the BC, NS and

Table 3. Mean preference scores for digital images for the combination of type, shape and background color (Expt. B) for British Columbia (BC), Nova Scotia (NS), and New Zealand (NZ) consumers.

\begin{tabular}{lccccccccr}
\hline $\begin{array}{l}\text { Apple } \\
\text { no. }\end{array}$ & Type & Shape & color & $\mathrm{mean}^{z}$ & $\mathrm{SE}^{\mathrm{y}}$ & $\begin{array}{c}\mathrm{NS} \\
\mathrm{mean}^{z}\end{array}$ & $\mathrm{SE}^{\mathrm{y}}$ & $\begin{array}{c}\mathrm{NZ} \\
\mathrm{mean}^{\mathrm{z}}\end{array}$ & $\mathrm{SE}^{\mathrm{y}}$ \\
\hline B1 & solid-red & round & NA & 9.9 & 0.28 & 10.0 & 0.30 & 9.2 & 0.39 \\
B2 & solid-red & oblong & NA & 8.1 & 0.35 & 8.7 & 0.30 & 7.8 & 0.40 \\
B3 & stripe & round & green & 8.6 & 0.29 & 7.8 & 0.30 & 9.5 & 0.32 \\
B4 & stripe & round & yellow & 9.5 & 0.28 & 8.1 & 0.30 & 9.2 & 0.30 \\
B5 & stripe & oblong & green & 7.3 & 0.32 & 7.3 & 0.33 & 8.9 & 0.35 \\
B6 & stripe & oblong & yellow & 9.5 & 0.30 & 7.2 & 0.33 & 8.4 & 0.39 \\
B7 & blush & round & green & 9.5 & 0.24 & 9.3 & 0.26 & 8.7 & 0.30 \\
B8 & blush & round & yellow & 8.5 & 0.31 & 8.4 & 0.25 & 8.1 & 0.32 \\
B9 & blush & oblong & green & 9.2 & 0.24 & 9.2 & 0.26 & 9.0 & 0.28 \\
B10 & blush & oblong & yellow & 9.0 & 0.34 & 8.8 & 0.26 & 7.6 & 0.35 \\
\hline
\end{tabular}

"Sensory scores were collected on a 12.5-cm hedonic line scale, labelled with "dislike-very-much," "dislikemoderately," "neither-like-nor-dislike," "like- moderately," and "like-very-much" at 0,3,6.3, 9.5, and 12.5 $\mathrm{cm}$, respectively.

y'Least significant difference between means is about three standard errors (SE) (Hall, 1997).

${ }^{\mathrm{NA} N o t}$ applicable. 
NZ consumers selected red apples from among red, green and yellow complimentary apples. Their selections were consistent with the fact that the solid-red apples were the most preferred.

\section{Conclusions}

This research demonstrated the usefulness of digital imagery for consumer research. It allowed images to be varied systematically for the evaluation of factors responsible for consumer preference. Consumer preference of apples was shown to be influenced by color, shape, type and background color. Some factors were consistent among all testing locations, e.g. red colored apples were generally preferred, while oblong apples were least preferred. Other factors were location-dependent. For example, NS consumers preferentially liked blush apples, while NZ consumers tended to prefer striped apples. The results of this research will assist apple breeders and marketing agencies in making decisions related to commercialization of new cultivars in the global market. This work demonstrated that the use of digital imagery is a powerful tool for controlling variation in visual samples. With this control, a more precise determination can be made of the relative impact of specific attributes on consumers.

\section{Literature Cited}

Andani, Z. and H.J.H. MacFie. 2000. Fruit and vegetable quality: An integrated view, p. 158177. In: R.L. Shewfelt and B. Bruckner (eds.). Consumer preference, Chapter 9.

Canadian Horticultural Council. 1979. A survey of Canadian consumers concerning apples and other fresh fruit. Ronalds-Reynolds and Co., Toronto.

Cliff, M., K. Sanford, and E. Johnson. 1999. Comparison of hedonic scores and R-indices for visual, flavour and texture preferences of apple cultivars by British Columbian and Nova Scotian consumers. Can. J. Plant Sci. 79:395399.

Crassweller, R.M. and R.A. Hollender. 1989. Consumer evaluation of 'Delicious' apple strains. Fruit Var. J. 43(4):139-142.

Cochran, W.G and G.M. Cox. 1957. Experimental Designs. Wiley, New York.

Dalliant-Spinnler, B., H.J.H. MacFie, P.K. Beyts, and D. Hedderley. 1996. Relationship between perceived sensory properties and major preference directions of 12 varieties from the south- ern hemisphere. Food Quality and Preference 7:113-126.

Leonard, R.L. and J.J. Wadsworth. 1989. Consumer preferences: A guide to Connecticut apple marketing. Food Marketing Policy Center Res. Rpt. No. 4, Univ. of Connecticut.

Hall, J.W. 1997. The presentation of statistical results in journal articles. Can J. Plant Sci. 77:11-14.

Hampson, C.R. and H.A. Quamme. 2000. Use of preference testing to identify tolerance limits for fruit visual attributes in apple breeding. HortScience 35:921-924.

Hampson, C.R., H.A. Quamme, J. Hall, R.A. MacDonald, M. King, and M.A. Cliff. 2000. Sensory evaluation as a selection tool in apple breeding. Euphytica 111:79-90.

Goedegebure, J., H. Barendse, and F. Pladdet. 1990. For the sake of the consumer. Dutch Fruit Growers' Organization, The Hague, Netherlands.

Lyman, B. 1989. A psychology of food-More than a matter of taste. Van Nostrand Reinhold Co., New York.

Stebbins, R. 1994. Consumer's tastes in apple varieties profiled. Good Fruit Grower 10:32-33.

von Alvensleben, R. and T. Meier. 1990. The influence of origin and variety on consumer perception. Acta Hort. 259:151-161.

Warner, G. 1991. Fruit quality is great, but exactly what is it? Good Fruit Grower 42:22. 